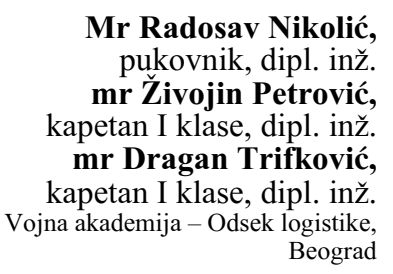

Mr Radosav Nikolić,

pukovnik, dipl. inž.

mr Živojin Petrović,

kapetan I klase, dipl. inž.

mr Dragan Trifković,

kapetan I klase, dipl. inž.

Vojna akademija - Odsek logistike,

Beograd

\section{IZVORI SUMOVA NA BRODOVIMA I PUTEVI NJIHOVOG RASPROSTIRANJA UNUTAR BRODSKIH KONSTRUKCIJA}

UDC: $623.82: 534.23$

Rezime:

U radu su opisani izvori šumova na brodovima i putevi njihovog rasprostiranja unutar brodskih konstrukcija. Obrađen je uticaj oscilacija konstrukcija na intenzitet šumova. Prikazane su spektralne karakteristike šuma koje proizvode motori na brodovima, norme šumnosti na brodovima, zaštitna sredstva od buke (opšta, lokalna i individualna), kao i osnovne metode za smanjenje šumova na brodovima.

Ključne reči: brod, brodska konstrukcija, šumovi, buka, prenos zvuka, zaštitna sredstva, izolacija.

\title{
NOISE SOURCES ON SHIPS AND NOISE DISTRIBUTION INSIDE THE SHIP STRUCTURE
}

Summary:

This paper presents noise sources on ships and the ways of its distribution inside the ship structure. The influence of structure oscillations on the noise intensity has been also explained. There is a review of noise spectrum characteristics of common ship engines, marine noise standards, noise protection equipment (overall, local and individual) as well as basic methods of noise prevention.

Key words: ship, ship structure, noise, transfer of sound, protection means, isolation.

\section{Uvod}

Osnovni izvori šumova na brodovima nastaju kao posledica rada glavnih i pomoćnih brodskih mašina (pogonski motori, parne i gasne turbine, pumpe, kompresori, ventilatori, separatori goriva i maziva i drugi). Šumovi se javljaju pri radu opšte brodske i mašinske ventilacije, brodskih sistema za pretakanje goriva, klima uređaja i uređaja opšte namene kod velikih brodova (liftovi, sanitarni čvorovi i sl.). Postoje i drugi izvori šumova koji se uslovno mogu smatrati sekundarnim, a nastaju kao posledica trenja slabo spojenih podnica, cevovoda i drugih metalnih delova i konstrukcija, kod kojih se javljaju oscilacije pri kretanju broda. Oscilacije se mogu javljati u oblasti infrazvučnih frekvencija, kao zveckanje, lupanje i brujanje.

Na putničkim brodovima, na putnike, pored šumova nastalih od mašinskih uređaja i mehanizama, negativan uticaj imaju i šumovi nastali zbog prisustva drugih putnika, koji se manifestuju preko: glasnog razgovora $i$ smeha $u$ susednim prostorijama, dečje vriske, bata koraka po hodnicima i palubama i sl. Svi navedeni izvori šumova nalaze se unutar broda. 
Šumovi mogu nastati pri radu brodskih propelera, posebno u uslovima pojave kavitacije ili zbog tonalnog oglašavanja usled oscilacija krila propelera. U krmenim prostorima broda šumovi mogu nastati zbog oscilacija krmene oplate, periodičnog zapljuskivanja pogonskih propelera, kao i zbog sopstvenog šuma propelera izazvanog oscilacijama i implozijama vazdušnih kaverni na krilima propelera u uslovima kavitacije. Poseban uticaj ispoljavaju šumovi koji nastaju zbog kavitacije pogonskih uređaja u toku manevrisanja broda [1].

$\mathrm{Na}$ brodovima sa podvodnim krilima (hidrokrilni brodovi) šumovi su vrlo izraženi, a nastaju zbog udara talasa o dno i trup broda, a na ledolomcima zbog udaranja trupa broda o led. Na brodovima sa vazdušnim jastukom šumovi nastaju kao posledica rada snažnih ventilacionih mašina i vazdušnih propelera (elisa).

\section{Šumovi na brodovima}

Na brodovima su moguća dva različita puta za prenos zvuka od izvora do mesta prijema. Prvi je vazdušni put, kod koga zvuk ne menja sredinu kroz koju se prostire, a drugi put je kroz čvrsta tela (brodska konstrukcija) koja osciluju, pri čemu se buka prenosi putem oscilacija. $\mathrm{Za}$ ovu buku upotrebljava se i termin „strukturna buka“ [3]. Na mestu prijema ovih oscilacija stvaraju se zvučni talasi u vazdušnom prostoru tako da ih čulo sluha može registrovati. Izuzetak predstavljaju oscilacije koje na članove posade brodova deluju neposredno, na primer tako što pod (paluba i sl.) na kome oni stoje osciluje. Uticaj ovih oscilacija naročito dolazi do izražaja u oblasti infrazvuka.
One su neprijatne, ometaju članove posada brodova i, u mnogo čemu, njihovo dejstvo je slično dejstvu buke [3].

$\mathrm{Na}$ brodovima su mogući sledeći putevi prenosa zvuka (prikazani na slici 1):

1. Prenos zvuka kroz zidove, podove, pregrade i palube, oscilovanjem konstrukcija (slično oscilovanju membrana) i ima talasni karakter.

2. Prenos zvuka kroz prozorske otvore, palubne otvore, ventilacione kanale, proreze, slabo zaptivena vrata i sl.

3. Prenos akustičkih oscilacija preko fundamenata i brodskih konstrukcija može izazvati pojavu buke u susednim i udaljenim prostorijama. Prenos zvuka u susedne prostorije, koji nastaje od pobudnih oscilacija raznih zaštitnih konstrukcija, smatra se sekundarnim. Pošto je to obično mala zvučna energija, pri dobro izvedenoj zvučnoj izolaciji može se smanjiti nivo šuma u susednim prostorijama.

Odnos između nivoa šuma koji se prenosi raznim putevima, zavisi od karaktera njegovog izvora i konstrukcije akustične zaštite prostora. Za uređaje sa velikim nivoom šuma (ventilatori), koji

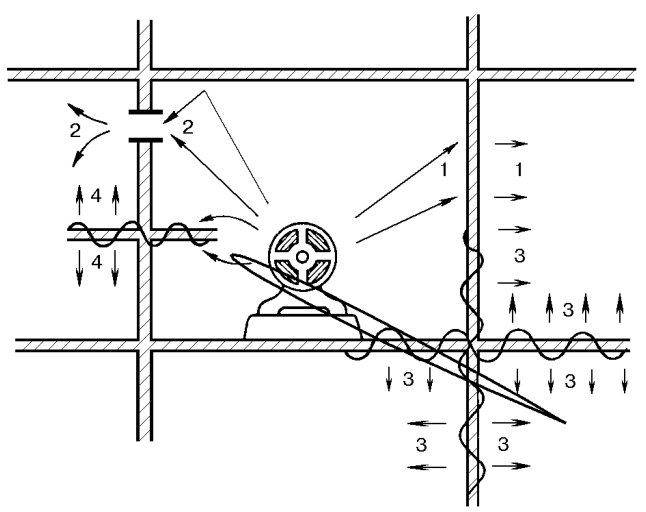

Sl. 1 - Putevi prenosa zvučnih oscilacija od izvora zvuka do susedne prostorije:

1 - kroz pregrade; 2 - kroz otvore u pregradama; 3 - na temelj $i$ konstrukciju mašinskog prostora; 4 - pomoću uzbude (nadražaja) pregrada ili obloga 
su ugrađeni u slabo izolovane prostore ili prostore sa velikim brojem otvora, osnovni putevi prenosa zvuka svrstani su pod 1 i 2. Pri radu takvih mehanizama, kod kojih se oscilujuća energija pretvara prvenstveno u zvučne oscilacije (dizel motori, pumpe, kompresori) šum u susednim i udaljenim prostorima prenosi se uglavnom trećim načinom. To se posebno odnosi na mehanizme bez amortizera, koji su postavljeni na lake temelje, i u prostorima sa dobrom zvučnom izolacijom. U brodskim prostorima, koji su udaljeni od izvora oscilacija, šum se uvek javlja kao posledica zvučnih oscilacija koje se prenose putem brodske konstrukcije. $\mathrm{Na}$ osnovu toga može se zaključiti da u brodskim prostorima koji su udaljeni od izvora šumova i oscilacija nije svrsishodno izvoditi kvalitetnu izolaciju od šumova koji se prenose vazdušnim putem, nego naprotiv - težište treba da bude na izolaciji zvučnih oscilacija.

Na slici 2 prikazan je spektogram u prostorima pogonskog kompleksa. Specijalne mere za smanjenje šuma na brodu $u$ prikazanom slučaju nisu predviđene.

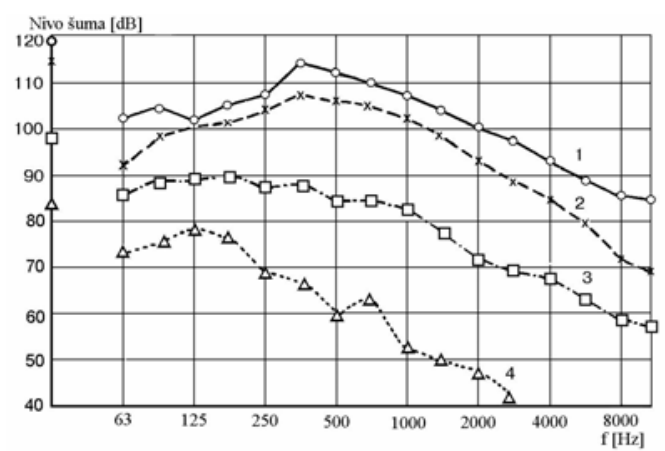

Sl. 2 - Spektri i nivoi šuma u prostorima pogonskog kompleksa:

1 - u mašinskom prostoru između dizel generatora 2 i 3; 2 - na donjoj rešetki ventilacionog otvora; 3 - u centralnom upravljačkom pultu (vrata mašinskog prostora zatvorena); 4 - u ambulanti
Kako se vidi iz grafikona (markacije na vertikalnoj osi) nivo šuma u nekim prostorima dostiže znatnu vrednost. U mašinskom prostoru nivo šuma iznosi 115 do $118 \mathrm{~dB}$ (re $20 \mu \mathrm{Pa}$ ) [3], a na izla$\mathrm{zu}$ ventilacione cevi za ubacivanje vazduha u prostorije premašuje prag ljudskog bola (u zavisnosti od frekvencije nivo šuma kreće se u granicama od 110 do $130 \mathrm{~dB}$ ) [3]. U brodskoj ambulanti (i nekim drugim kabinama) nivo šuma dostiže 81 do $83 \mathrm{~dB}$. Spektralne krive prikazuju da maksimalni nivo šuma u mašinskom prostoru zauzima oblast od treće do pete oktave, što znači da definisana norma šumnosti za brodove nije ispunjena. Van mašinskog prostora najviši nivo u spektru šuma susreće se na nižim frekvencijama, što je uslovljeno oscilacijama na nižim frekvencijama koje se slabije izoluju i amortizuju pri rasprostiranju kroz brodsku konstrukciju.

Nivo šuma na brodu sa dizel pogonom, pri promeni režima plovidbe od „lagano“ do „punom snagom“, unutar brodskih prostorija menja se za 4 do 5 $\mathrm{dB}$. Ako je brod na vezu, kada rade samo pomoćni dizel motori (generatori), nivo šuma je, takođe, visok i premašuje nivo pogonskih motora pri režimu plovidbe „lagano“. U mašinskom prostoru uvek se javlja šum visokog nivoa, zbog rada glavnih motora (slika 3). Na mostovima i palubama srednjeg nadgrađa, koji su od mašinskog prostora odvojeni nepropusnim međuprostorima i izduženim konstrukcijama trupa, nivo šuma je za 30 do $40 \mathrm{~dB}$ niži nego u mašinskom prostoru.

Motori zauzimaju relativno mali deo površine mašinskog prostora, zbog čega postoji velika mogućnost ugradnje kon- 


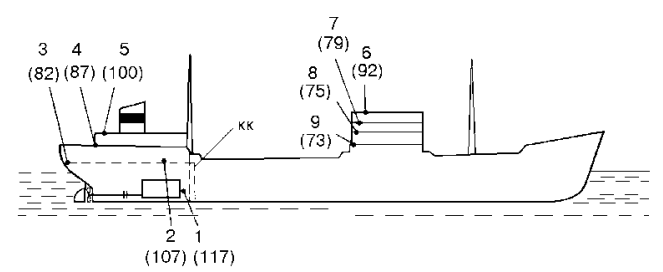

Sl. 3 - Nivo šuma (brojevi u zagradama) $u$ mašinskom prostoru, na palubama i mostu tankera:

1 - u mašinskom prostoru; 2 - na krmenoj palubi iznad pogona; 3 - u krmenom delu gornje palube; 4 - u krmenom delu iznad pogona; 5 - na gornjoj krmenoj palubi; 6 - na otvorenom delu donjeg mosta; 7 - u donjem mostu; 8 - na centralnom mostu; 9 - na gornjoj neprekidnoj palubi; $K K-u$ krmenom vodonepropusnom meduprostoru

strukcija za izolaciju i apsorpciju zvuka. $\mathrm{S}$ obzirom na to da takve konstrukcije $\mathrm{u}$ razmatranom slučaju nisu ugrađene, prisutan je bio visoki nivo šuma kako blizu dizel motora (110 do $117 \mathrm{~dB})$ tako i na mestu za upravljanje (105 do $110 \mathrm{~dB}$ ).

Nivo šuma dizel generatora u prostorijama tegljača - gurača u zavisnosti od vrste amortizera

\begin{tabular}{|l|c|c|}
\hline \multirow{2}{*}{ Naziv prostorije } & \multicolumn{2}{|c|}{ Nivo šuma, [dB], pri radu: } \\
\cline { 2 - 3 } & $\begin{array}{c}\text { Levog dizel } \\
\text { generatora } \\
\text { (postavljenog na } \\
\text { gumene } \\
\text { amortizere) }\end{array}$ & $\begin{array}{c}\text { Desnog dizel } \\
\text { generatora } \\
\text { (postavljenog na } \\
\text { opružne } \\
\text { amortizere) }\end{array}$ \\
\hline $\begin{array}{l}\text { Prostor dizel } \\
\text { generatora }\end{array}$ & 105 & 106 \\
\hline Salon & 85 & 74 \\
\hline $\begin{array}{l}\text { Kabina prvog } \\
\text { mašiniste }\end{array}$ & 93 & 79 \\
\hline $\begin{array}{l}\text { Kabina drugog } \\
\text { mašiniste }\end{array}$ & 88 & 72 \\
\hline $\begin{array}{l}\text { Kabina trećeg } \\
\text { mašiniste }\end{array}$ & 88 & 74 \\
\hline Kabina kapetana & 75 & 72 \\
\hline Radio-kabina & 81 & 71 \\
\hline Navigaciona kabina & 81 & 69 \\
\hline
\end{tabular}

U tabeli je prikazan nivo šuma na snažnom rečnom tegljaču - guraču. Prikazani podaci pokazuju da na malim brodovima šumovi u svim prostorijama, osim mašinskog prostora, nastaju kao posledica zvučnih oscilacija konstrukcije
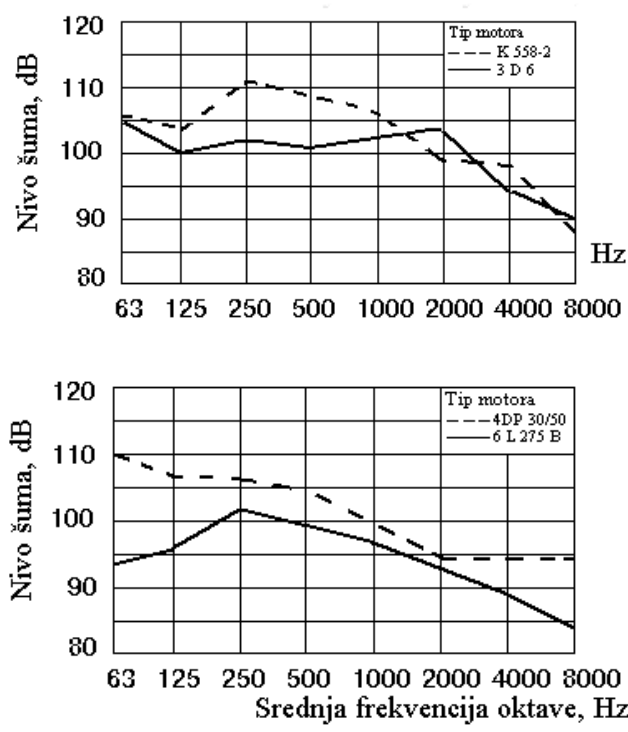

Sl. 4 - Spektralne karakteristike šuma koji se prenosi vazdušnim putem i zvučnih oscilacija nekih tipova brodskih dizel motora

trupa. Promenom karakteristika amortizera moguće je smanjiti nivo oscilovanja motora, pri čemu se šumovi u svim prostorijama znatno smanjuju, mada šum motora koji se prenosi vazdušnim putem ostaje nepromenjen.

Na slici 4 prikazane su spektralne karakteristike šuma i zvučnih oscilacija nekih tipova brodskih dizel motora, dobijene na osnovu rezultata izbora i proračuna malošumnih amortizujućih sklopova.

$\mathrm{Na}$ slici 5 prikazan je spektogram šuma u prostorima broda sa podvodnim krilima. Primećuju se znatni nivoi šuma, naročito na niskim frekvencijama.

\section{Norme šumnosti na brodovima}

Danas u svetu postoje norme dozvoljenog nivoa šuma na brodovima. Krive dozvoljenih nivoa šuma opadaju sa povećanjem frekvencije (slika 6), što odgovara zahtevima za smanjenje štetnih viso- 


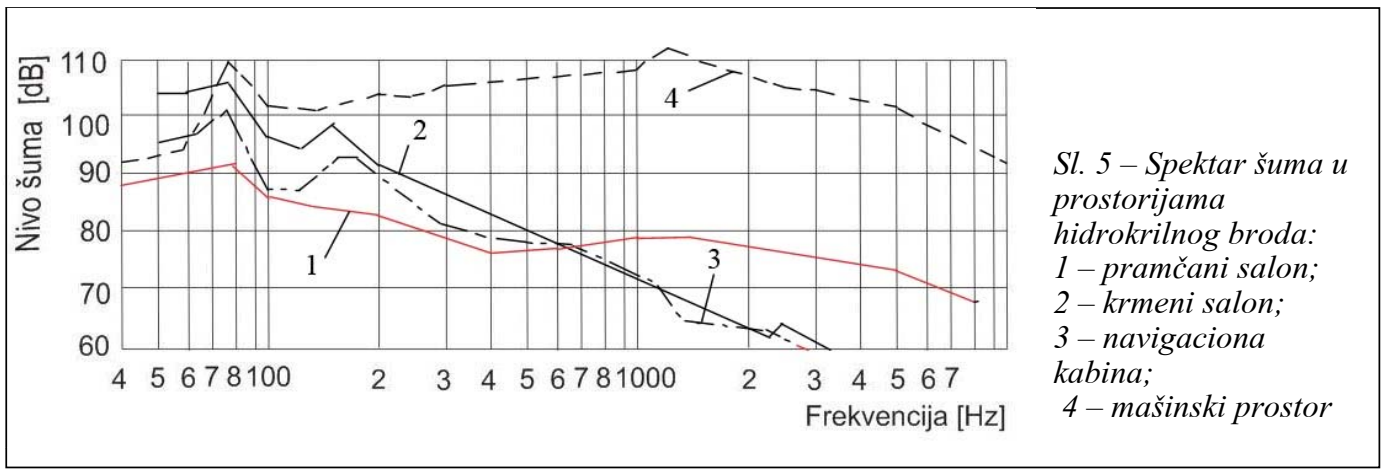

kofrekventnih komponenti šuma. Norme su ustanovljene za mašinske i službene prostore, kao i prostore za stanovanje, na osnovu vremena trajanja šuma. Pri periodičnom delovanju šuma dozvoljena spektralna kriva je za $10 \mathrm{~dB}$ viša nego kod njegovog neprekidnog delovanja (slika 6a). Treba napomenuti da se na brodovima, kod kojih nivo šuma prelazi granične vrednosti (kriva 1), moraju koristiti lična zaštitna sredstva (antifoni, čepovi za uši, šlemovi i sl.), radi zaštite pri obilasku mašinskog prostora, kada su pogonske mašine u radu.

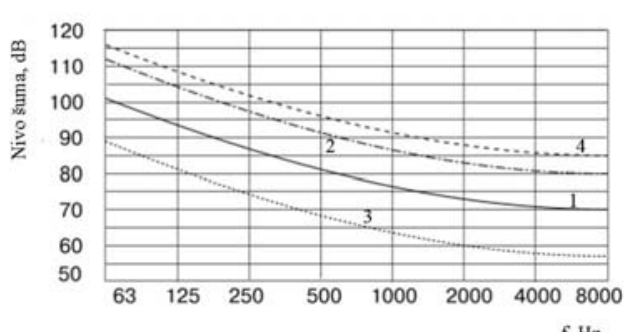

Sl. $6 a-$ Granične vrednosti dozvoljenih nivoa šumova u mašinskim prostorima i izolovanim prostorima za upravljanje:

1 - pri radu u mašinskom prostoru u toku cele smene (7 ili više časova); 2 - pri periodičnom radu u mašinskom prostoru u toku smene (opšte vreme delovanja šuma najviše 120 minuta u toku dana); 3 - u izolovanim prostorima za upravljanje; 4 - u mašinskim prostorima brodova koji su opremljeni sredstvima kompleksne automatizacije
U prostorima za stanovanje i službenim prostorima najviši dozvoljeni nivoi šuma su kod brodova sa podvodnim krilima (kriva 4 slika 6b), što je uslovljeno nizom teškoća vezanim za smanjenje šumova na tim brodovima. Za neke kategorije brodova dozvoljeno je i premašivanje norme, ali ne za više od $3 \mathrm{~dB}$ u bilo kojoj oktavi ili poluoktavi opsega. Pri merenju nivoa šuma u poluoktavnom opsegu, krive opadaju za $3 \mathrm{~dB}$, a pri merenju u jednotrećinskom oktavnom opsegu za $5 \mathrm{~dB}$ u odnosu na podatke prikazane na grafikonima.

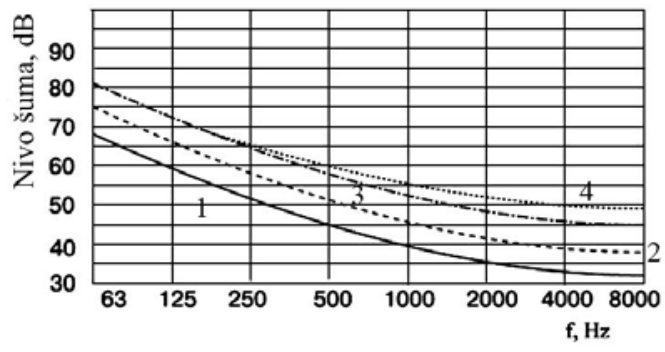

Sl. $6 b$ - Granične vrednosti dozvoljenih nivoa šumova u ličnim, zajedničkim i službenim prostorijama broda:

1 - na morskim brodovima koji plove više od 24 časa; 2 - na morskim i rečnim brodovima koji plove do 24 časa; 3 -na morskim i rečnim brodovima koji plove do 8 časova; 4 - na morskim i rečnim brodovima $i$ komandnim prostorima i putničkim salonima hidrokrilnih brodova 
Normama su obuhvaćeni način merenja šuma na brodovima, kao i određena pravila vezana za sprečavanje štetnog dejstva šuma na brodsku posadu, kao što su: postavljanje, gde god je to moguće, daljinskog upravljanja radom glavnih $i$ pomoćnih mašina; promena režima rada $\mathrm{i}$ odmora posade, radi smanjenja vremena neprekidnog izlaganja buci.

Za svakog člana pogonskog brodskog kompleksa vodi se tzv. slušni karton. Kada se kod lica između dva godišnja medicinska pregleda ustanove odstupanja u slušnom pragu, ili pogoršanje opšteg zdravstvenog stanja organizma, oni se moraju obavezno premestiti na radna mesta gde nema štetnog uticaja buke.

\section{Zadaci, metode i sredstva za smanjenje šumova na brodovima}

Postoje dva praktična zadatka brodske akustike vezana za smanjenje šumova na brodovima, a to su: smanjenje neprijatnog osećaja i jačine šuma i povećanje razgovetnosti verbalne komunikacije.

Rešenje prvog zadatka zahteva, pre svega, slabljenje za percepciju najneprijatnijih oscilacija visoke frekvencije. Pri izdavanju i prijemu komandi, i pri telefonskim razgovorima između članova posade i putnika, treba obezbediti dovoljno dobru razumljivost govora. To spada u teži zadatak, jer zahteva smanjenje šuma u oblasti osnovnih komponenti govora (300 do $3000 \mathrm{~Hz})$ a po mogućnosti i u oblastima nižih frekvencija. Za povećanje razumljivosti telefonskih razgovora $u$ uslovima šuma primenjuju se elektroakustičke metode, kao što je rezanje maskirnih oscilacija niske frekvencije.
Pri projektovanju brodova velike tonaže pojavljuju se konstrukciono-akustični problemi, koje treba rešavati slično prethodno navedenim. Takav zadatak susreće se pri rešavanju problema optimalnog vremena reverberacije i stvaranja ravnomerne čujnosti u muzičkim salonima, amfiteatrima za nastavu i bioskopskim salama. Jedan od načina rešenja problema je akustična obrada unutrašnjih površina prostorija, koja istovremeno omogućava i smanjenje šuma. Treba imati u vidu da nanošenjem na zidove prostorija velikog broja slojeva prigušivača zvuka, radi smanjenja nivoa šumnosti, za posledicu može imati pogoršanje reverberacionog režima. Problem se može rešiti uvođenjem veštačke reverberacije.

Osnovne metode za rešavanje problema šumova su: smanjenje šumova $i$ oscilacija na izvorima njihovog postanka i izolacija i gušenje šumova koji se prenose vazdušnim putem kao i zvučnih oscilacija.

Pozitivni efekti, takođe, mogu se postići racionalnim rasporedom prostorija i opreme koja predstavlja izvor šuma u njima, i izborom tipova i uređaja koji najbolje ispunjavaju akustičke zahteve.

Pored navedenih postupaka treba imati u vidu i principe koji imaju direktan uticaj na proces stvaranja i rasprostiranja zvuka i oscilacija. Oni se odnose na sprečavanje ili otklanjanje oscilacija konstrukcija i dodirivanja metalnih elemenata, smanjenje emisionih površina šuma, promenu impedance pobuđivača i emitera oscilacija i sl.

Najefikasnije mere za smanjenje štetnog uticaja buke i zvučnih oscilacija odnose se na otklanjanje uzroka njihovog nastajanja. Međutim, ovo je često 
nemoguće praktično izvesti. Preduzete mere mogu biti: opšte, lokalne ili individualne [4]. U opšte profilaktičke mere spadaju izbor tehnološkog procesa i mašina koje emituju manje buke, izolovanje svih izvora zvuka oblaganjem njihovih unutrašnjih površina materijalima koji apsorbuju buku, merenje i kontrola svih vrsta buke i oscilacija. Opšta zaštita može nekada da snizi nivo buke i za 20 $\mathrm{dB}$ sa relativno skromnim ulaganjima. $\mathrm{U}$ drugu grupu spadaju presvlake za zvučnu izolaciju mehanizama, postavljanje raznih vrsta akustičnih kabina, apsorbujućih ekrana, pregrada i štitova. U ovu grupu može se svrstati i akustična obrada ventilacionih kanala, postavljanje specijalnih ventilacionih prigušivača, prigušenje izduvne i usisne grane motora, ugradnja prigušivačkih uređaja $\mathrm{u}$ prostorima za boravak i odmor, kao i na putevima unutar brodskog transporta. Primena navedenih apsorbujućih sredstava za posledicu može imati promenu arhitekture i akustičnog režima prostora u celini. U sličnim slučajevima ta sredstva je svrsishodnije usmeriti na razvoj opštih zaštitnih sredstava od buke. Individualne preventivne mere zaštite sastoje se u upotrebi zaštitnih sredstava (čepova za uši, štitnika ili kaciga) koje, ako su dobro izrađene, mogu imati izolacioni efekat i preko $30 \mathrm{~dB}$.

Najefikasnija sredstva za izolaciju zvučnih oscilacija konstrukcija su amortizeri, elastični spojevi i priključci, elastični umeci i podloške sa malim akustičnim otporom. U posebnim slučajevima, za izolaciju oscilacija nastalih zbog ugiba relativno tankih ploča mogu se koristiti mase za ublažavanje oscilacija. One mogu biti formirane ne samo u obliku stvar- ne sopstvene mase, nego i u obliku konstrukcionih brodskih elemenata - podebljanja palubnih otvora, rebara i sl.

Smanjenje zvučnih oscilacija, u širokom dijapazonu frekvencija, moguće je postići pomoću specijalnih pokrivača za apsorpciju oscilacija koji se nanose na fundamente i konstrukcije trupa. Slični pokrivači danas se sve više primenjuju u automobilskoj $\mathrm{i}$ avio industriji. Za apsorpciju intenzivnih niskofrekventnih oscilacija sve veću primenu nalaze antivibratori, koji se postavljaju na određenim mehanizmima, ležajima glavnog pogonskog vratila, palubi i sl. Antivibracioni sistemi sastoje se od elemenata mase, elastičnosti i trenja, a mogu se koristiti za apsorpciju i izolaciju oscilacija nastalih zbog ugiba ploča na zvučnim frekvencijama (apsorberi strukturnog zvuka). Fiziološko dejstvo intenzivnih oscilacija smanjuje se upotrebom antivibracionih uložaka koje brodska posada stavlja u obuću.

Za prigušenje šumova motora primenjuju se, pored konstruktivnih mera koje ublažuju pojavu kavitacije i „penjenja“ propelera, i akustična sredstva izolacije. Potrebe za sredstvima za zaštitu od buke određuju se već u fazi projektovanja broda. Željeni akustični efekat postiže se, po pravilu, samo pri istovremenoj primeni svih raspoloživih mera za smanjenje akustičnog šuma. Znatan broj lokalnih zaštitnih sredstava može na brodu biti ugrađen naknadno u toku remonta ili modernizacije. Metode zvučne izolacije i izolacije zvučnih oscilacija i njihove apsorpcije, promene impedancije i smanjenje oscilujućih sila primenjuju se i neposredno kod konstrukcije brodskih mehanizama i sistema, radi smanjenja šumova i zvučnih oscilacija pri njihovom radu [1]. 


\section{Zaključak}

Pored osnovnih šumova, na brodovima se često javljaju i sekundarni šumovi, kao posledica trenja i oscilacija slabo spojenih metalnih elemenata konstrukcije broda. Ovi šumovi često se nalaze $u$ oblasti infrazvučnih frekvencija. Na brodu se zvuk prenosi kroz pregrade, podove i palube na nižim frekvencijama, i putem oscilacija konstrukcija na višim frekvencijama. Na prenos zvuka posebno utiče konstrukciono rešenje ugradnje mašina i mehanizama koji predstavljaju izvor zvučnih oscilacija. Ugradnjom odgovarajućih amortizera između mašine, odnosno mehanizma i fundamenta broda, na kojem su oni montirani, smanjuje se prenos zvuka preko konstrukcije kao i njene zvučne oscilacije, ali ostaje zvuk koji se prenosi vazdušnim putem. Radi smanjenja buke potrebno je izvršiti dodatnu zvučnu izolaciju ugradnjom odgovarajućih apsorpcionih materijala, kako bi se postigle odgovarajuće norme šumnosti na brodu. Pri tome koriste se odgovarajuće metode za smanjenje šuma $i$ oscilacija na izvorima njihovog nastanka. Za zaštitu članova posade od buke neophodna je upotreba zaštitnih sredstava (opštih, lokalnih i individualnih).

Metode za izolaciju buke, prigušenje oscilacija, povećanje apsorpcije zvuka i promene impedancije, koriste se pri projektovanju brodske konstrukcije i izboru brodskih mašina i mehanizama. Međutim, nemoguće je potpuno eliminisati pojavu šumova, odnosno buke, ali ih je moguće ublažiti, tj. smanjiti za nekoliko desetina decibela (10 do $30 \mathrm{~dB}$ ).

\section{Literatura:}

[1] Клюкин, И. И.: Боръба с шумом и звуковои вибрациеи на судах, Леннинград, 1971.

[2] Зинченкоб В. И., Захаров, В. К.: Снижение шума на судах, Леннинград, 1968

[3] Kurtović, H.: Osnovi tehničke akustike, Beograd, 1990.

[4] Simonović, M.; Kalić, D.; Pravica, P.: Buka, štetna dejstva, merenja i zaštita, Niš, 1982. 